\title{
Pragmatic Analysis of Compliments among A Female Egyptian Teachers in Ismailia City
}

\author{
Rehab Alaa El-din Saad Abdel-Hameed \\ English Department, Faculty of Arts and Humanities, Suez Canal \\ University, Ismailia.
}

ABSTRACT: Appropriate compliments are an aspect of communicative competence which may differ from one culture to another (Mikey, 2013). Teacher to teacher effective communication is essential for the success of the school society. The aim of the present study was to describe the syntactic patterns, structural formulae and topics variations and functions characterizing the compliments among female Egyptian teachers in Ismailia City. Fifty female Egyptian teachers in Language Schools, in Ismailia city, aged from 25 years old to Retirement were included in the study. A written English and Arabic Discourse Completion Test (DCT) was used to elicit data of giving and receiving compliments. Based on Yuan, 2002, classification: 79.0\% of the compliments were explicit unbound semantic formulas, only $6.6 \%$ were implicit compliments. The researcher's proposed classification showed that a majority of the compliments were inclusive of a praying component (34.2\%), while $18.3 \%$ included reference to God; this reflects a 
religious background of the complimenters, declarative, exclamatory compliments were the dominant compliment's categories used. Precision, exaggeration, payback, misconceptions, being self-centered, preaching are unique compliments categories used by the participants. Compliments were expressed in the context of the Arabic language and Egyptian culture context; as language and culture are closely intertwined. The present study draws the attention of teachers to the importance of communicative and sociolinguistic competence; which could improve communication and communication skills between teachers of different seniority levels among female Egyptian teachers in Ismailia City.

Keywords: Compliments; Female Egyptian teachers; discourse completion Test

تعتبرالبحاملات تعبيرا لفظيا عن الإنفعالات الإيجابية الدالة على الإستحسان والتقبل،

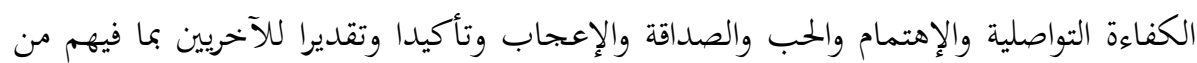

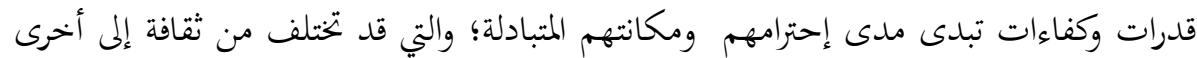

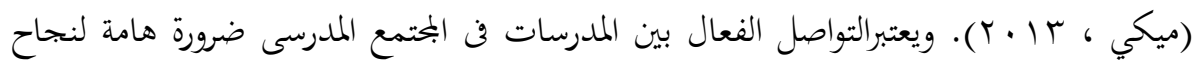

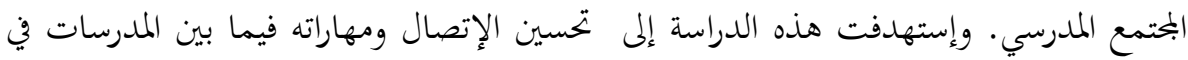

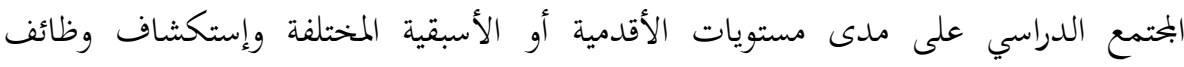

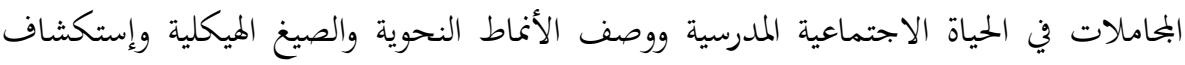

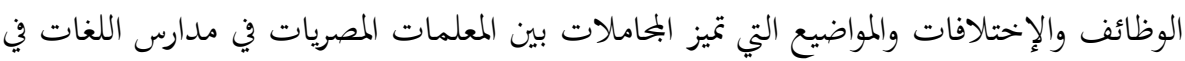

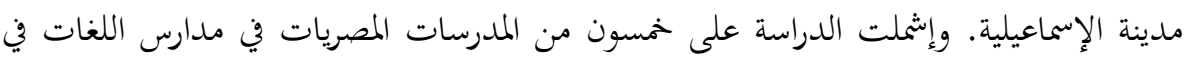

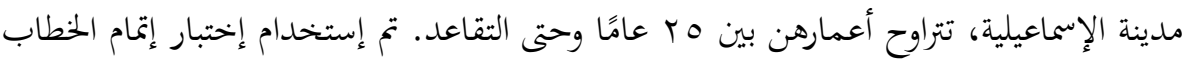
المكتوب باللغتين الإنحليزية والعربية (DCT) لإستنباط البيانات عن تقديم وإستقبال البحاملات. 


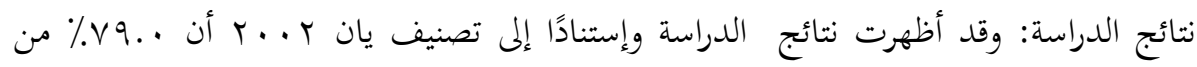

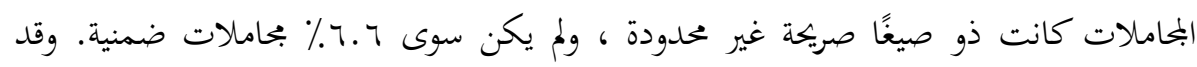

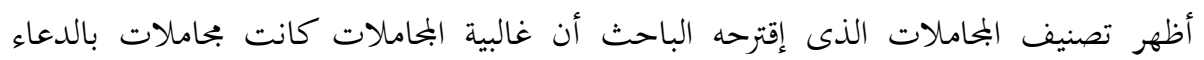

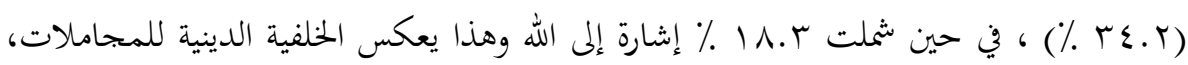

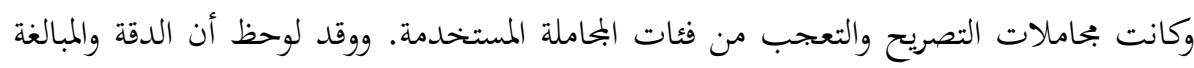

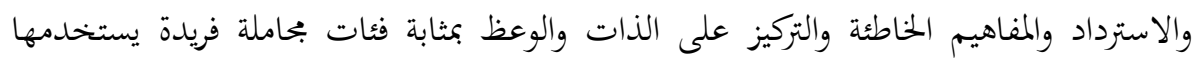

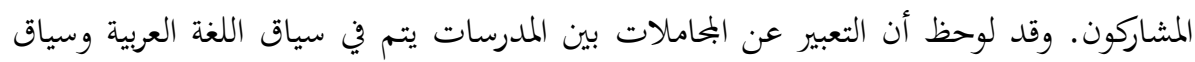

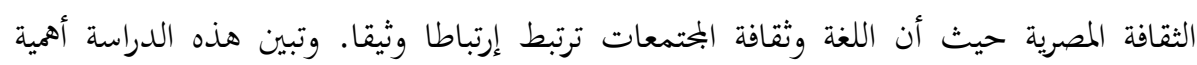

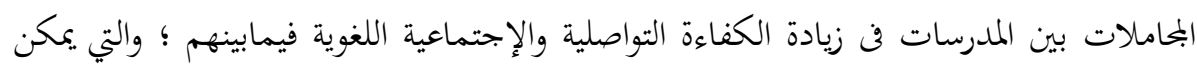

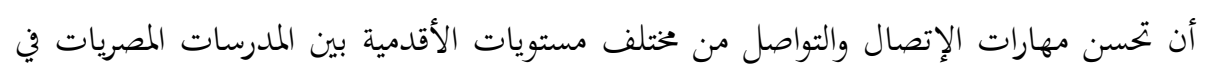

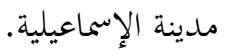

Introduction: Developing pragmatic competence needs experience, knowledge and language awareness. According to Fasold (2006) "Pragmatics concerns both the relationship between context of use and sentence meaning, and speaker's meaning. The speech act of people complimenting maintains and creates a special relationship and improves people's actions. The early studies by Manes \& Wolfson (1981) reported that the formulaicity of compliments in American English, knowing when and how to compliment verbally while adhering to the norms and conventions of the language used in any speech act leads to successful communication. It is well known that compliments differ according to many factors: social, environmental, residency, educational level, special situations, events, race, and religion which are included among the crucial factors. 
The school society has its own entity like other human societies, as it must be dominated by an atmosphere of intimacy, love, cooperation, and other human relationships, which enable us to communicate and interact easily and flexibly. Teachers are the most significant resource in schools, as they are essential in raising education standards. Improving the efficiency and equity of schooling depends in large measures on making sure that teachers are highly skilled, well resourced, and motivated to perform at their best. Teachers should pay more attention to rules of pragmatics in complimenting; lack of pragmatic competence may cause failure in communication. It is not sufficient to emphasize the grammatical aspects of the English language; teachers should also emphasize the appropriate usage of language in complimenting and compliment response. Previous works on complimenting illustrated that context plays an essential role in figuring out the true interpretation of compliments, the influence of compliments on social success compared with the role of oxygen in breathing (Knapp et al., 1984). Compliments are largely subconscious; it is necessary to collect and analyze compliment patterns across cultures to avoid cross-cultural misunderstanding; moreover, complimenting can be direct or indirect and requires careful interpretation beyond linguistic norms (Wolfson, 1981). Teacher to teacher effective communication is vitally essential to teacher success as an efficient teacher, and teacher team collaboration are extremely valuable. Moreover, education 
which is a highly difficult concept for those outside the educational field to understand, necessitates the presence of peers that can collaborate with and lean on during tough times and is considered critically essential. Categories of compliments: According to Yuan, 2002, there are two main categories of compliments in terms of the semantic formulas used to express them (Table 1).

Overview of the compliment Functions: Like other speech acts, and from a chronological point view of the previous studies (Holmes, 1988; and Duan, 2011), compliment functions can be collectively summarized as follows: To start or begin a dialogue between people, to make the dialogue continue smoothly, to show the speaker's commendation and approval for others' appearance, performance, to begin, maintain and strengthen rapport and solidarity, to substitute other speech acts such as apology, congratulation and greetings, to make the effect of criticism and other face threatening acts soft, to encourage the addressee's desired performances and traits, to reduce social distance between the addresser and addressee, not only compliments make the one who receives it happy, but also charges the one who gives it a positive energy. Nataly Kogan (2018) (a social network founder focused in collecting and sharing happy moments with other users), reported that earlier studies showed that getting a sincere compliment gives us the same positive boost as receiving cash; the health and 
happiness benefits to the compliment giver are also welldocumented.

Characteristics of effective Compliments: Mikey (2013) reported that paying appropriate compliments and identifying them accurately is an aspect of communicative competence; which may differ in a variety of ways from one culture to another. The author suggested and described characteristics of effective compliments, which could provide the necessary context for the tips that could be followed: Be Genuine: Only praise someone if you think they actually deserve it. Be Specific: being specific is always better. Be unique: this is related to being specific, but it goes a bit deeper. Acknowledge their effort: Chances are good that it took some effort for the other person to achieve whatever it is you are complimenting them on. Describe the effect something has on you: While praise is ultimately about the other person, they must have had some effect on you in order for you to notice it. Use emotional or descriptive Language: This is an important point, but if you don't have a way with words, you shouldn't let it stop you from complimenting others, if you can, however. Don't be backhanded: sometimes, people will give compliments that make the other person feel worse about themselves, don't do that, a compliment should be entirely positive, and should leave no room for a negative interpretation. Don't wait for the perfect moment: the timing of your compliment is important; but 
the perfect moment will never come. Don't second-guess yourself: own your compliment, whatever you have to say, say it like you mean it, you do mean it, right? if you are wishy-washy about it, your compliment will completely lose its effect. Pause for effect; after saying what you need to say, stop for a moment, give it a moment to sink in, it's not as though your compliment should be a conversation stopper. Don't expect anything in return; sometimes we compliment others because we want to get something back from them, this is a bad place to be coming from, remember, the compliment is for them.

Aim of the present study was to describe the syntactic patterns, structural formulae and topics variations and functions characterizing the compliments among female Egyptian teachers in Ismailia City; to investigate the importance of communication, among teachers of various seniority levels, within the educational field.

Research Methodology: Participants: The present study is descriptive study, conducted in language schools, Ismailia City, Egypt. The target population were fifty female Egyptian teachers in language schools, in Ismailia city, aged from 25 years old to Retirement.

Instrument: A written Discourse Completion Test (DCT) (in English and Arabic) was used to elicit data from female Egyptian teachers in Ismailia City (Appendix-1). The 
application of DCTs in pragmatic and discourse studies has not been without controversies. Golato (2005) emphasizes that the DCT allows the researcher to control certain variables, and to quickly gather large amounts of data without any need for transcription, thus making it easy for statistical analysis. The topics are: family affairs and marriage (engagement party, wedding party, birth of the first baby). Education (admission to school to the first grade, success in various grades, admission to the university, graduation from university party). Health issues (visiting a sick colleague, recovery after illness). Work and Jobs (application for a job opportunity, assignment to a new job, promotion at work, attendance of a honorifical party). Travelling (vacation short trip, travel to work abroad, travel for professional training, travel for specialized professional certificates). Public events (survived an accident without injury, winning of the issue in court).

Procedures: The DCT was designed in English and Arabic versions; and five English language Egyptian experts in the field of pragmatic research revised the content both grammatically and semantically. The DCT was then modified based on the received feedbacks. There were five situations provided in the DCT and the participants were required to write down suitable compliments for each situation. Respondents were asked to provide information about their age, gender, place of birth, education level, field of study, 
native language, and email address. Respondents were also allowed to provide comments on the DCT. Participants were informed to provide a written compliment in different situations included in the five main topics of the DCT. It is true that some respondents may not have experienced the situations given in the survey; but they all may know the norms through which they should provide the most contextually appropriate response. After making sure of the reliability and validity of the DCT, the following procedures were conducted by the researcher:

1- Distribution of the DCT to the target population of the study after revision and permission by the Directorate of Education, Ismailia Governorate; participants consent was taken before conducting the study.2- collecting and classifying the data in order to be analyzed. 3-Analyzing and discussing the study findings. 4- Finally, offering conclusions and recommendations of the study.

Data Analysis: The collected data were entered into a Microsoft Excel worksheet, and then each compliment had its frequency calculated, and classified into categories. The data were statistically analyzed using the SPSS statistical program, specifically using the frequencies and percentages, in addition to the Chi-square test and T-test. The present study employed a framework proposed by Yuan, 2002 to analyze different compliment patterns used by the participants. The participants' responses to the situations 
provided were divided into three types: Compliment, Noncompliment and Opt out (Table-1). Both descriptive and inferential statistics were used to analyze the compliment sentences. At the first phase, the frequency of each compliment as well as the percentages was identified. Each compliment sentence was assigned a function (Explicit, Implicit, or Opt-out) and the number of different functions in each group was considered as the total frequency of responses in that group.

Detailed data analysis: In the present study, the collected data were analyzed to define the following detailed classifications regarding compliment categories and behavior:

1-Distribution of different compliments categories based on compliments classification proposed by Yuan, 2002.

2-Distribution of different compliments categories; proposed by the researcher (Alternative classification), based on results obtained following collected data analysis.

3-Modifications to the basic compliment structure (Miscellaneous compliment situations).

The statistical analysis of the collected data is divided into two sections:

I-Demographic data. II-Analysis according to category of compliment. 
I- Demographic data: included analysis and description regarding age distribution of the participants; it is assumed that age may have some influence on the participants' responses. Junior versus senior (age groups) teachers in the study responded to compliment situation in different ways (table-2).

Table -2: Age distribution of the Study Population

\begin{tabular}{|l|c|c|c|}
\hline \multicolumn{2}{|c|}{ Age ranges } \\
\hline Variables & Attributes & Mean \pm & $\begin{array}{c}\text { p- } \\
\text { SD }\end{array}$ \\
& & & \\
\hline
\end{tabular}




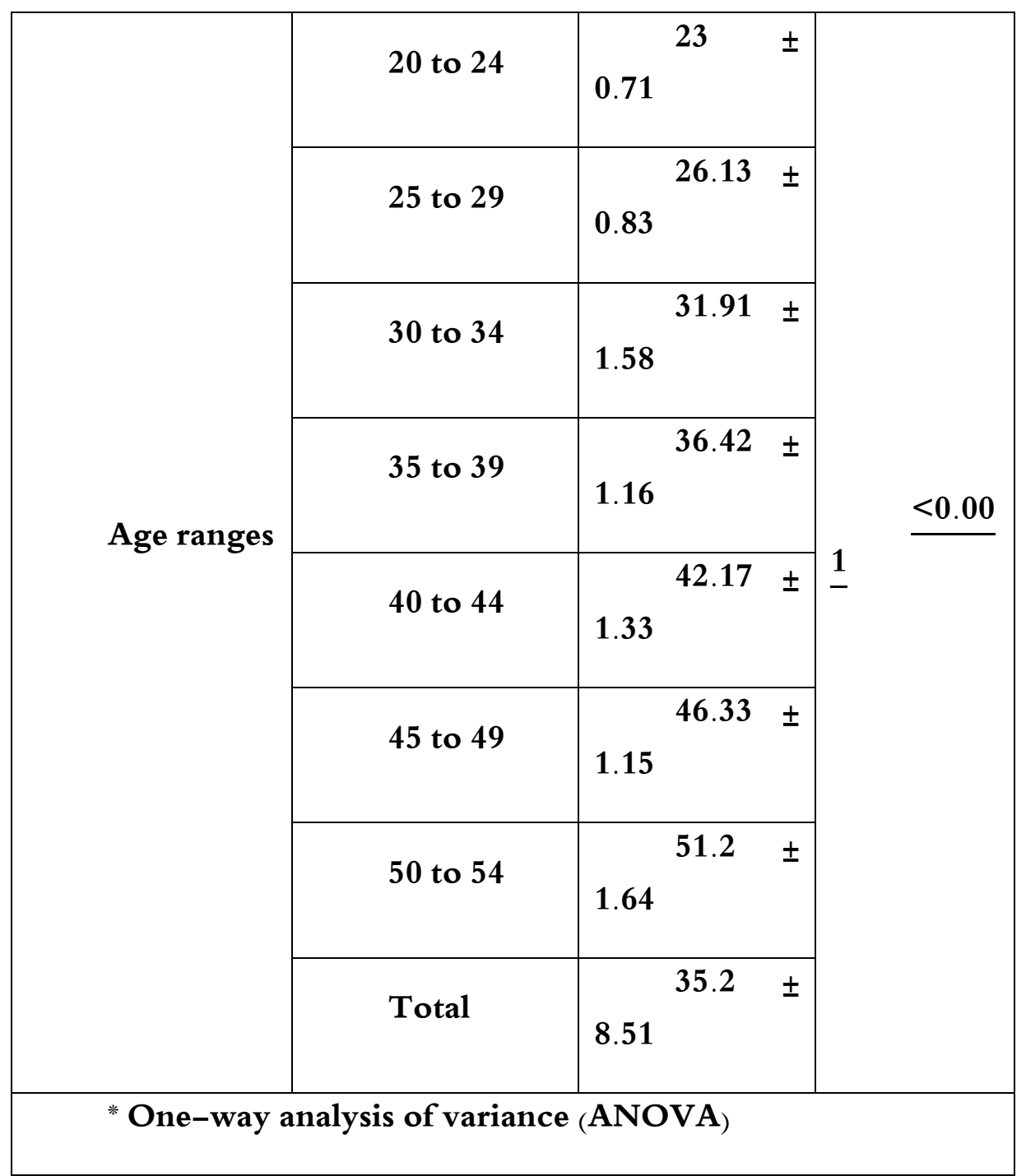

There was a statistically significant difference between

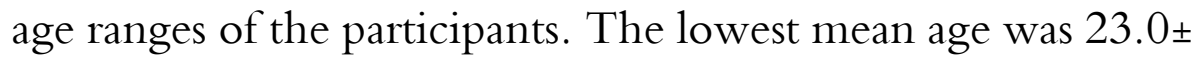
0.71 years old and the highest mean age was $51.2 \pm 1.64$ years old (table-2), which means that the study population included the whole spectrum of teachers with variable ages with different life experience. 
Table -3 : The age distribution of the study population classified according to seniority and official position levels:

\begin{tabular}{|c|c|c|c|c|}
\hline Seniority & & & & \\
\hline Variables & $\begin{array}{l}\text { Attribute } \\
\text { s }\end{array}$ & $\begin{array}{r}\text { Mean } \\
\pm \text { SD }\end{array}$ & $\begin{array}{r}\mathrm{p} \\
\text { value }\end{array}$ & \\
\hline \multirow{3}{*}{ Seniority } & Junior & $5.27^{31.14 \pm}$ & \multirow{3}{*}{$01^{*}$} & \multirow{3}{*}{$<0.0$} \\
\hline & Senior & $4.11^{46.77 \pm}$ & & \\
\hline & Total & $8.51^{35.2 \pm}$ & & \\
\hline \multirow{5}{*}{ Position } & $\begin{array}{l}\text { Class } \\
\text { Assistant }\end{array}$ & $0.58^{23.33 \pm}$ & \multirow{5}{*}{\multicolumn{2}{|c|}{$01 a^{<0.0}$}} \\
\hline & Assistant & 42 & & \\
\hline & $\begin{array}{l}\text { Senior } \\
\text { Teacher }\end{array}$ & $3.54^{44.5 \pm}$ & & \\
\hline & $\begin{array}{r}\text { Co- } \\
\text { Teacher }\end{array}$ & $3.511^{26.33 \pm}$ & & \\
\hline & Teacher & $7^{34.38 \pm}$ & & \\
\hline
\end{tabular}




\begin{tabular}{|c|c|c|c|}
\hline & $\begin{array}{c}\text { Head of } \\
\text { Department }\end{array}$ & 35 & \\
\hline & Monitor & $\begin{array}{ll} & 49 \quad \pm \\
2.83 & \end{array}$ & \\
\hline & Expert & $3.21^{48.67 \pm}$ & \\
\hline & $\begin{array}{l}\text { Social } \\
\text { Worker }\end{array}$ & 32 & \\
\hline & Total & $8.51^{35.2 \pm}$ & \\
\hline $\begin{array}{r}* \text { Independ } \\
\text { variance (ANOV }\end{array}$ & $\begin{array}{l}\text { Ant samples } t \text {-test } \\
\text { A) }\end{array}$ & o One-way & analysis of \\
\hline
\end{tabular}

Table-3 shows that: There were statistically significant differences in between seniority and official position variables attributes' regarding mean ages. The highest mean age for seniors was 46.77 years old; while that of the monitors which was 49.0 years old.

Table-4: The distribution of the study population among educational program \& educational grades:

\begin{tabular}{|l|l|l|l|}
\hline \multicolumn{3}{|l|}{} \\
\hline Variables & Attributes & $\mathbf{n}(\%)$ & $\mathbf{p}-$ \\
\hline
\end{tabular}




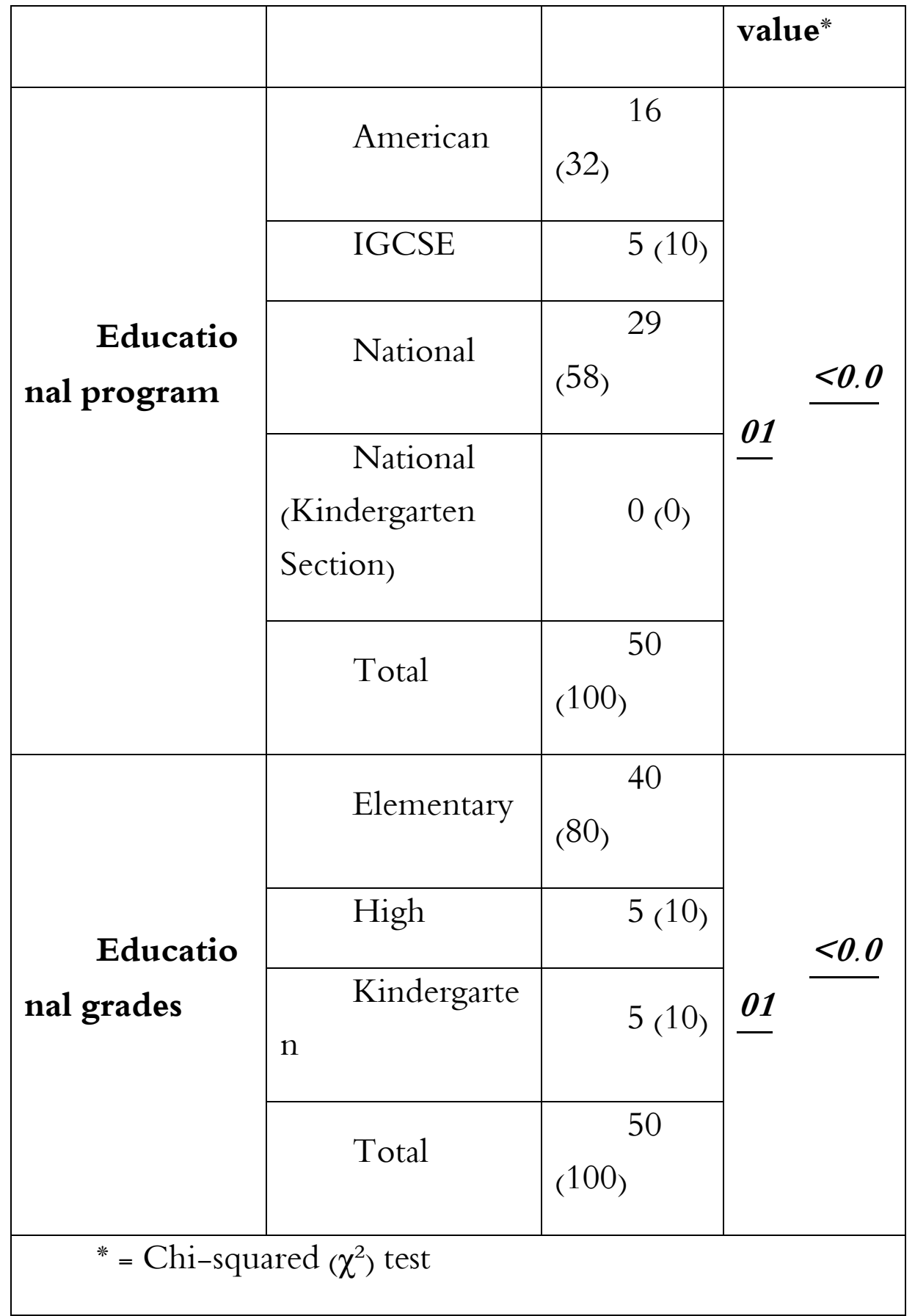

There were statistically significant differences regarding the distribution of study participants among educational 
program and educational grades. Most of the participants were in the national educational program. Elementary grade showed the highest frequency of study participants. There were statistically significant differences regarding the distribution of study participants among seniority, position and the educational subjects taught. Most of the participants were juniors; which could reflect the increased activity and the social abilities of the younger participants.

II- Analysis of the study participants according to the compliment's categories.

Table -5: The distribution of compliment's categories classified by educational program among the study population:

\begin{tabular}{|c|c|c|c|c|}
\hline $\begin{array}{r}\text { Type of } \\
\text { educational pr }\end{array}$ & $\begin{array}{l}\text { complin } \\
\text { gram }\end{array}$ & ent's catc & gory clas & sified by \\
\hline Types & $\begin{array}{c}\mathrm{A} \\
\text { merican }\end{array}$ & $\mathrm{CSE}^{\mathrm{IG}}$ & $\begin{array}{l}\text { Nati } \\
\text { onal }\end{array}$ & $\begin{array}{r}\mathrm{p}^{-} \\
\text {value }\end{array}$ \\
\hline $\begin{array}{l}\text { Declarativ } \\
\mathrm{e}(\%)\end{array}$ & $\begin{array}{ll} & 27 . \\
74 & \end{array}$ & 9.13 & 50.7 & \\
\hline $\begin{array}{l}\text { Exclamato } \\
\text { ry }(\%)\end{array}$ & $35 \quad 10$. & 2.70 & 19.0 & 0.90 \\
\hline Imperative & 0.0 & 0.35 & 0.17 & \\
\hline
\end{tabular}




\begin{tabular}{|c|c|c|c|c|}
\hline$(\%)$ & 0 & & & \\
\hline $\begin{array}{l}\text { Interrogati } \\
\text { ve }(\%)\end{array}$ & $35 \quad 10$. & 2.70 & $\begin{array}{r}19.0 \\
4 \quad 4\end{array}$ & \\
\hline$*=\mathrm{Chi}-$ & 1 & & & \\
\hline
\end{tabular}

Referring to table-5; it is evident that there were no statistically significant difference in between educational programs regarding compliment's categories. This means that there was no certain pattern attained different in educational programs from another one in compliment's categories. The compliments of participants working in the national educational program were both most declarative and exclamatory among sections. Compliments of participants working in the IGCSE educational program were most imperative, although the frequency was relatively low anyways (0.35\%). Teachers at the American educational program used the most interrogative data. Declarative, exclamatory and interrogative. were the least frequent compliments in IGCSE educational program.

Table -6: The distribution of the type of compliment's category classified by educational grades among the study participants:

Type of compliment's category classified by educational 


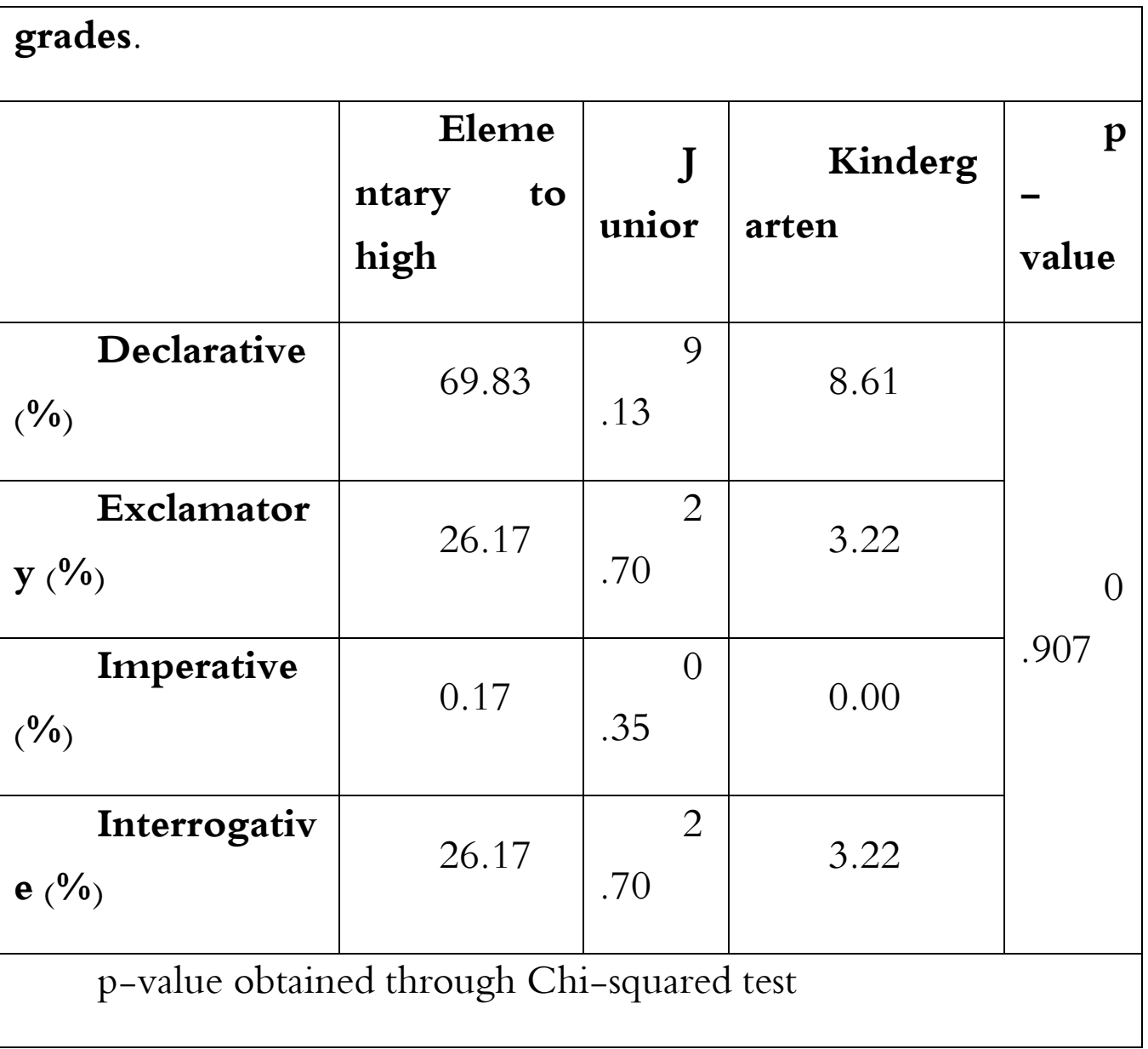

Referring to table-6; it is evident that there was no statistically significant difference among educational grades participants regarding types of compliment pattern. This means that there was no certain pattern attained different in educational grades participants from another one in complimenting. The highest frequency of all of the declarative, exclamatory and interrogative compliments were those given in the elementary to high educational grades. 
Junior educational grade compliments showed the highest frequency of imperative compliments, although the frequency was relatively low (0.35\%). The lowest frequency of declarative and imperative compliments was given in kindergarten educational grades participants. There were no exclamatory compliments in junior educational grade which showed the lowest interrogative compliments frequency. Subject matters or areas of educational background did not on the whole show much influence in the participants' responses. When senior versus junior teachers (age wise) responded to similar compliments, they did not show clear or statistically significant differences.

Table -7: Distribution of the type of compliment's category classified by seniority among the study population:

\begin{tabular}{|c|c|c|c|}
\hline $\begin{array}{l}\text { Type of } \mathrm{c} \\
\text { seniority }\end{array}$ & iment's & egory clas & ified by \\
\hline & Junior & \begin{tabular}{|l} 
Seni \\
or
\end{tabular} & $\begin{array}{r}p^{-} \\
\text {value }\end{array}$ \\
\hline $\begin{array}{l}\text { Declarative } \\
(\%)\end{array}$ & 63.65 & 23.91 & 0.8 \\
\hline
\end{tabular}




\begin{tabular}{|c|c|c|}
\hline $\begin{array}{l}\text { Exclamator } \\
\mathbf{y}(\%)\end{array}$ & 24.70 & 7.39 \\
\hline $\begin{array}{ll} & \text { Imperative } \\
(\%) & \end{array}$ & 0.17 & 0.35 \\
\hline $\begin{array}{l}\text { Interrogativ } \\
\text { e }(\%)\end{array}$ & 24.70 & 7.39 \\
\hline p-value ob & ugh & test \\
\hline
\end{tabular}

Referring to table-7; it is evident that there were no statistically significant difference in between sub-sections regarding types of responses. This means that there was no certain pattern attained different in a sub-section from another one in complimenting. Compliments given by the junior staff showed a higher frequency of declaration, exclamation and interrogation than those of seniors, but not imperativeness which showed the contrary.

Table -8: Classification of compliments by category

\begin{tabular}{|c|c|c|c|}
\hline Category & ute & n $(\%)$ & $\begin{array}{l}\text { p- } \\
\text { value }\end{array}$ \\
\hline \multirow{2}{*}{ Accepting } & Yes & $\begin{array}{l}677 \\
(92)\end{array}$ & \multirow[t]{2}{*}{$<0.00$} \\
\hline & No & $59(8)$ & \\
\hline
\end{tabular}




\begin{tabular}{|c|c|c|}
\hline & Total & $\begin{array}{l}736 \\
(100)^{2}\end{array}$ \\
\hline \multirow{3}{*}{ Declining } & Yes & $\begin{array}{l}41 \\
(5.6)^{4}\end{array}$ \\
\hline & No & $\begin{array}{l}695 \\
(94.4)^{6}\end{array}$ \\
\hline & Total & $\begin{array}{l}736 \\
(100)^{2}\end{array}$ \\
\hline
\end{tabular}

Table-8 shows that there was a statistically significant difference in the category of compliments distribution. This is congruent to the fact that there was a trend of accepting compliments within the study population of the current study. Most of the compliments were accepting in nature, and not down-grading.

Collectively, compliment's categories (declarative, exclamatory, imperative and interrogation compliments) there was no certain pattern attained in compliment's categories in spite of the dominance of the declarative, exclamatory compliments. In relation to different educational programs; the compliments of participants working in the national program were both most declarative and 
exclamatory among programs, compliments of participants working in the IGCSE program were compliments given by the junior staff showed a higher frequency of declaration, exclamation and interrogation than those of seniors.

\section{Classification of compliments categories:}

1-Distribution of different compliments categories based on compliments classification proposed by Yuan, 2002 showed that: $79.0 \%$ of the compliments were explicit and only $6.6 \%$ were implicit. $2.0 \%$ were of explanatory formula, question compliments constituted $2.3 \%$ and those which had future reference were $2.8 \%$, advising compliments were of $3.9 \%$ and those requesting constituted $0.3 \%$ of all of the compliments analyzed in the study, $3.1 \%$ of the compliments were non-complimenting and $0.9 \%$ were opting-out. Most of the compliments were accepting in nature, and not downgrading; these data could suggest that participants in the present study are complimentary and good-hearted, this can be deducted from the high frequency of explicit compliments and advising ones, non-complimenting compliments and those opting-out may be indicators of the non-sociability of those who gave them.

2-Distribution of different compliment categories proposed by the researcher (Alternative classification) showed that a majority of the compliments were inclusive of a praying component (34.2\%), and 18.3\% included reference 
to God; this reflects a religious background of the complimenters, which may be either related to the situation (situational) like (Blessed Ramadan!) or divine or related to ALLAH like for example (Praise ALLAH!). In addition, positive compliments include $27.7 \%$ congratulating, while $23.5 \%$ had wishes included; and $11.4 \%$ were of greeting nature in addition to $6.4 \%$ of supporting compliments; these categories of compliments could indicate compliments that are original in their nature and are related to the situation the complimentee is being complimented about.

Discussion: Compliment is a speech act that frequently occurs in everyday conversations; the influence of compliments on social success is compared with the role of oxygen in breathing. Compliment behavior may vary crossculturally; the school society has its own entity, teachers are the most significant resource in schools, teacher to teacher effective communication is vitally essential to a teacher success, an atmosphere of intimacy, love, cooperation is essential foundation for the success of the school society. Analysis of the collected data showed the following details regarding compliment categories and behavior classification:

1-Distribution of different compliments categories based on compliments classification proposed by Yuan, 2002 showed that: participants used direct compliments to create 
and reinforce solidarity between the addressees and themselves, also the participants were complimentary and good-hearted; this can be deducted from the high frequency of explicit compliments and advising ones, although frequency of advising compliments was not that high, It might indicate a small tendency of curiosity; referring to future referencing and information-questions. Some complimenters may be information-seekers or are requesters and/or demanders of explanation. The previous findings are supported by Yuan, 2002, as well as Jin-pei's (2013); the authors emphasized that people tend to make direct and positive statements when they are paying compliments. The second infrequently used strategy was non-compliments which accounts for $3.1 \%$ of the total responses; the relatively low frequency of non-compliments, i.e. not paying compliments when the situation calls for them, may be due to the fact that the respondents were not able to distinguish expression of thanks from expression of compliments; because borders between the two expressions are blurred. Also, this may be an indication of the non-sociability of those who gave them. Additional reason for non-compliments is that in real situations there might be an intrinsic ambiguity or that the respondents intend to use an avoidance strategy. Moreover, in some cases, thanking seems to be more common than complimenting. For example, it is common for people to thank the interlocutor because he/she has been listening to them for a long time than to compliment his/her 
kindness. The same findings were reported by shahidi \& Zarei, 2017 who reported that highly educated people tended to use explicit semantic formula strategy in complimenting. The female Egyptian teachers' compliments were expressed in the context of the Arabic language and Egyptian culture context. One must bear in mind that the speech event of compliments could not be interpreted apart from social and cultural context; because they relied on shared beliefs and values of the speech community coded into communicative patterns (Yousef vand, 2010, Yousef vand 2012). Similarly, Haliday (2003) suggested that this pragmatic variation among languages proves that language is not an object devoid of social and cultural elements, but it is a process which is inseparable from other of human social life. and emphasizes that language and culture were closely intertwined. The DCT used in the present study might favor the production of compliments which were direct explicit formulas. But if another researcher employs other methods to collect data (e.g., recording spontaneous speech, or role plays), results will probably change.

2-Distribution of different compliment categories proposed by the researcher (Alternative classification): a good number of the compliments were inclusive of a praying component $(34.2 \%)$, and $18.3 \%$ included reference to ALLAH. This reflects a religious background of the respondents/ complimenters. These compliment categories 
may be either related a specific situation (situational) like (Blessed Ramadan!) or divine or related to ALLAH like for example (Praise ALLAH). A mere positivity is evident in the compliments: $27.7 \%$ of the compliments were congratulating, 23.5\% had wishes included; and 11.4\% were of greeting nature in addition to $6.4 \%$ of supporting compliments. The positive compliments indicate either action-oriented compliments like offering to assist the person in the situation complimented about, or initiatory as in a pure compliment regarding the situation the complimentee is being complimented about. It could be seen that there were complimenters who were initiators; this is shown through a $6.8 \%$ action-oriented or proposing compliments, plus $1.4 \%$ of the compliments were of an offering nature. Only $0.3 \%$ of the compliments were of conditioned nature to the condition or the situation requiring a compliment or a response. The proposed classification could be explained on the fact that; compliments differ according to many factors; including social, environmental, residency, educational level, special situations, events; in addition, race and religion are included among the crucial factors. Compliments in Arabic are mainly derived from religious expressions, which are common in all Arab countries. Regarding Egyptian complimenting Mursy \& Wilson, 2001, proposed that compliments are culturespecific objects; based on their proposal, a model of Egyptian politeness was constructed that is culture-specific to Egyptian society. This model is based on the Social Contract of Values 
(SCV); Egyptians enter conversation equipped with a set of values that are socially sanctioned and institutionalized, according to which they are expected to behave in a certain way that enhances their reputation and image in the eyes of society. If they do not fulfil any of these values, they will be performing shameful behavior, at the most, or other less socially disapproved acts, at the least. Complimenting occurs in the light of the value of zooq (tact) and mugamla (courtesy), and through the maxims of generosity and approbation. Politeness, thus, is seen as a social contract of values that are socially accepted and expected in the behavior of individuals, the fulfilment of which brings to an individual the acceptance of 'good image' in society, and the breach of which brings to the individual varying degrees of social punishment, the maximum of which is shameful behavior.

3-Modifications to the basic compliment structure (miscellaneous compliment situations): which include: precision, exaggeration, payback, misconceptions, being selfcentered, preaching, in addition to infrequent unique responses. Precision: compliments were to the point, and very suitable to each occasion, without adding any extra word. Exaggeration: Most of the words like a thousand congratulations, compared to the European cultures people do not say these numbers, it is only congratulations. Payback: Egyptian females impatiently wait for any occasion, whether good or bad to express compliments. Misconceptions: It is 
said that: it is rude to say to a newly wedded couples "looking forward to your progeny", as if you are asking them when you are going to have a baby ?, may be they are not planning, or even did not plan for this yet. Being self-centered: participant talked about herself, her life, and her own experiences. Preaching: participants turned the whole issue to a group of advices to the complimentee.

4- Compliment was long, consisting of opening and ending sentence in English and Arabic. For instance, Goodbye, and thanks for everything you have done for me.

5- Participants complimenting in English and Arabic were using the same statements but translated into Arabic. They reasoned that whenever they were exposed to the same situation, they would act similarly regardless of the language.

6- Participants expressed their compliments directly using positive adjectives and verbs and indirectly using questions and requests. However, some participants failed to recognize the indirect compliments.

\section{Implication of the study:}

1-The study of compliments in the Egyptian context helps to provide in-depth insights on the communicative competence among female Egyptian teachers, the study explores the problems that which teachers face in using the 
language for social purposes, particularly when expressing compliments.

2-The study of compliments helps teachers to understand the culture in which they are operating, and to communicate successfully with other speakers in the school environments. This research draws the attention of teachers to the communicative competence; and how their communicative competence can be improved in order to better interact with others. Teachers may consider changing the teaching activities and instructional methods they use in their classes in order to allow learners to use language from a communicative perspective. Teachers might change from depending on the mere instruction of grammar and vocabulary to using interactive activities and tasks that stir the students' thinking and evaluation.

3-This study could enable syllabus designers to consider students' needs when designing syllabuses. Syllabus designers might consider incorporating materials that allow teachers to practice language in a manner which promotes linguistic competence as well as pragmatic competence.

4-Teacher development programs can benefit from this research in developing teachers' abilities to design their classes and to design class materials that ensure students' crosscultural understandings and allow learners to communicate effectively with speakers from other backgrounds. 


\section{References:}

Duan, Yuanbing (2011): "A Pragmatic Research Report on Compliment Speech Act". Theory and Practice in Language Studies; 1 (4): 356-360.

Fasold, R. (2006): An Introduction to Language and linguistic. Publisher: Cambridge University Press (2006-0313). ASIN: B01FKUV4B8.

Golato A (2005): Compliments and Compliment Responses: Grammatical Structure and Sequential Organization. Amsterdam, Philadelphia: J. Benjamins Pub. Co. ISBN 1-58811-599-2 
Holmes, J (1988a): "Paying Compliments: A SexReferential Politeness Strategy". Journal of Pragmatics; 12: 445-465.

Holmes, J (1988b): Compliment and compliment responses in New Zealand English. Anthropological Linguistics; 28: 485-508.

Jin-pei, Z (2013): Compliments and compliment

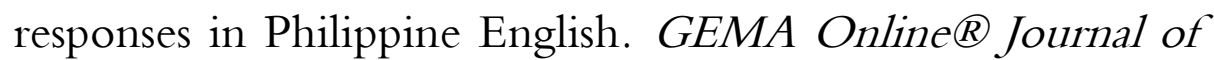
Language Studies; 13 (1): 25-41.

Knapp, M L, Hopper, R \& Bell, R A (1984): Compliments: A Descriptive Taxonomy. Journal of Communication; 34: 12-31. doi:10.1111/j.1460-2466.1984. tb 02185.x

Manes, J \& Wolfson, N (1981): The compliment formula. In Coulmas, F. (ed.), Conversational Routine. The Hague: Mouton, 115-132.

Mikey, D (2013): http://feel happiness.com/characteristics of great compliments/ Footnotes-1. http: // online library. wiley.com/ doil 10.1111/j. 1559-1816. 2007.00247. x /abstract.

Mursy, A A \& Wilson, J (2001): Towards a definition of Egyptian complimenting. Multilingual; 20 (2): 133-154. 
Nataly Kogan, (2018): Happier now. Sounds True, Boulder Co. 80306, Canada.

Shahidi Vahid and Zarei Gholam Reza (2017): Investigating the Use of Compliments and Compliment Responses in Persian: Effect of Educational Background. International Journal of Applied Linguistics \& English Literature; 6 (1): 227-238.

Yousef vand, Z (2010): Study of compliment speech act realization patterns across gender in Persian. Arizona Working Papers in SLA \& Teaching; 17: 91-112.

Yousef vand, Z (2012): A Sociolinguistic Perspective: Compliment Response Patterns in Persian. The Internet Journal of Language, Culture and Society; 34: 68-77.

Yuan, Y (2002): Compliments and compliment responses in Kunming Chinese. Pragmatics; 12 (2): 183 226.

Table 1. Yuan, 2002, Framework of Compliment Strategies 


\begin{tabular}{|c|c|c|}
\hline \multicolumn{2}{|c|}{ Compliment Strategies } & Example \\
\hline \multirow{3}{*}{\begin{tabular}{|l|} 
Unbound \\
Semantic \\
Formulas
\end{tabular}} & Explicit & What a nice cell phone you have. \\
\hline & Compliment & \\
\hline & $\begin{array}{l}\text { Implicit } \\
\text { Compliment }\end{array}$ & $\begin{array}{l}\text { I wish I could have a cell phone like } \\
\text { yours. }\end{array}$ \\
\hline \multirow{7}{*}{$\begin{array}{l}\text { Bound } \\
\text { Semantic } \\
\text { formulas }\end{array}$} & Explanation & I saw how difficult it was to fix my \\
\hline & Information & Where did you learn to fix it? \\
\hline & Question & \\
\hline & $\begin{array}{l}\text { Future } \\
\text { Reference }\end{array}$ & $\begin{array}{l}\text { You have a bright future in fixing } \\
\text { laptops. }\end{array}$ \\
\hline & Contrast & $\begin{array}{l}\text { I think you are more helpful than } \\
\text { your brother. }\end{array}$ \\
\hline & Advice & You'd better open a laptop store. \\
\hline & Request & Can you check my cell phone too? \\
\hline \multicolumn{2}{|c|}{ Non-Compliment } & Sorry to take your time \\
\hline \multicolumn{2}{|l|}{ Opt Out } & I would say nothing. \\
\hline
\end{tabular}

